\title{
Trimerization of Isobutene over Solid Acid Catalysts: Comparison between Cation-exchange Resin and Zeolite Catalysts
}

\author{
Ji Woong Yoon, ${ }^{+\neq}$Sung Hwa Jhung, and Jong-San Chang.* \\ ${ }^{\dagger}$ Research Center for Nanocatahsts, Korea Research Institute of Chemical Technologv, P.O. Box 107, Yusung, \\ Daejeon 305-600, Korea. ${ }^{*}$ E-mail jschangakrict.re.kr \\ "Department of Chemical and Biological Engineering, Korea Lniversity, Seoul 136-701, Korea \\ ${ }^{\$}$ Department of Chemistry Kuthgpook Kational Lniversity, Daegu 702-701, Korea. ${ }^{*}$ E-email: sumgaknu.ac.kr \\ Recerved December 6, 2007
}

\begin{abstract}
Catalytic trimerization of isobutene to produce triisobutenes has been performed over cation-exchange resin and zeolite catalysts. Resin catalysts have the advantage of long lifetime and high trimers selectivity even though the regeneration of an aged catalyst is not satisfactory. On the contrary. zeolite catalysts can be regenerated facilely by simple calcination in air even though the lifetime is short and trimers selectivity is low probably due to small pore size and strong acidity. respectively. It is. therefore highly desirable to develop an inorganic acid cataly st with macro- or meso-pores to show catalytic performances similar or superior to those of macroporous resin catalysts.
\end{abstract}

Key Words : Isobutene. Trimerization. Zeolite, Cation-exchange resin

\section{Introduction}

Recently. trimerization of light olefins has attracted considerable attention as a method for the production of fuel additives ${ }^{l}$ and separation of isoolefins from other olefins." Triisobutenes. for example. are considered to be highly useful for the sy'nthesis of specialty chemicals. "Triisobutenes. after hydrogenation. can be used as premium solvents and additives for kerosene and jet fuel. ${ }^{3}$

A surplus of isobutene is expected because the blending of MTBE (methyl-tert-butyl ether) in gasoline has been banned in California ${ }^{4}$ since 2004 due to contamination caused by the dissolution of MTBE in underground water. Hence. the trimerization is a very promising reaction not only for the utilization and separation of isobutene but also for the production of isobutene trimers. Nevertheless. the trimerization of isobutene has not received adequate attention in comparison with the dimerization of olefins. ${ }^{5-1 !}$ Several solid acid catalysts such as a sulfated titania. ${ }^{1.11 .12}$ a cation exchange resin. .13 a heteropoly acid ${ }^{14}$ and a zirconia ${ }^{15}$ have been suggested for the trimerization reaction.

Recently. we have reported the isobutene trimerization over a few solid acid catalysts such as beta (BEA) zeolite. ${ }^{16}$ ferrierite (FER) zeolite. ${ }^{17} \mathrm{FeCl}_{3}$-loaded $\mathrm{HY}$ zeolite ${ }^{18}$ dealuminated $\mathrm{HY}$ zeolite ${ }^{15}$ and cation exchange resins. $13.20=1$ Not only the effect of Lewis acid sites ${ }^{16-19}$ but also the effect of process conditions ${ }^{20}$ and butadiene ${ }^{21}$ were discussed. In this article. we conducted the isobutene oligomerization reaction over cation-exchange resin and zeolite catalysts in order to compare the effectiveness of the catalysts for commercial application in isobutene trimerization and to suggest possible way to develop a promising catalyst. Especially. we focused on the lifetime. trimers selectivity and regenerability of the catalysts.

\section{Experimental}

Trimerization of isobutene ( $99 \%$. Rigas Korea) was carried out in the liquid-phase using a fixed bed continuous flow reactor (OD $3 / 8$ inch. stainless steel 316 ) equipped with a back pressure regulator (Tescom). The reaction temperature and pressure of the reaction were $70^{\circ} \mathrm{C}$ and 15 bar. respectively. unless otherwise specified. The reactor temperature was maintained constant by a water jacket in which water. kept at constant temperature. was flowing continuously with the help of a circulator. The reactant (isobutene) and a diluent ( $n$-butane. 99\%. Rigas Korea) were continuously fed by using liquid mass flow controllers (Bronkhorst HI-TEC). The space velocity of isobutene. WHSV (weight-hourly space velocity, g-isobutene/g-dried catalyst/h) was varied between $10-50 \mathrm{~h}^{-1}$ by controlling the flow rates of isobutene and $n$-butane. The feeding rates of the isobutene and the diluent were reported in $\mathrm{wt} \%$. and the concentration of isobutene was $50 \mathrm{wt} \%$. unless otherwise specified.

Several commercial solid catalysts including cation exchange resins and zeolites were used in this study. Cation exchange resins (Amberlyst-15 and Amberlyst-35). macroporous and containing sulphonic acids. were purchased from Rolum and Haas. Zeolites such as beta (BEA. CP 814E. $\mathrm{SiO} / \mathrm{Al}_{2} \mathrm{O}_{3}=25$. surface area $=680 \mathrm{~m}^{2} / \mathrm{g}$ ) and ferrierite (FER, 9l4C, $\mathrm{SiO}_{2} / \mathrm{Al}_{2} \mathrm{O}_{3}=20$, surface area $=400 \mathrm{~m}^{2} / \mathrm{g}$ ) were purchased from Zeolyst in ammonium forms. The catalysts were used without further purification. The zeolite catalysts were calcined at $550^{\circ} \mathrm{C}$ for $8 \mathrm{~h}$ in a muffle furnace to convert anumonium forms into protonated forms. The extra water $(\sim 50 \mathrm{w} \%)$ that remained in the cation exchange resins was not removed or replaced because water-containing cation exchange resins do not show bad performance after the water is replaced with reactants. ${ }^{13}$ Catalysts $(0.2-0.5 \mathrm{~g}$ on dry 
base. together with five times of quartz beads for dilution) were loaded in the reactor as beads (cation exchange resins) or pellets (zeolite). Prior to the conmencement of the reaction. the zeolites loaded in the reactor were dehydrated at $300^{\circ} \mathrm{C}$ for $10 \mathrm{~h}$ under the flow of nitrogen.

The conversion of isobutene was determmed by analyzung frequently the composition of the off-gas strean by using a GC equipped with a TCD and an alumina columin (J\&W Scientific, $30 \mathrm{~m} \times 0.53 \mathrm{~mm}$ ). The conversion was crosschecked by measuring the total flow rates of isobutene and the diluent, after condensing liquid products, with a mass flow meter (Brooks, $5850 \mathrm{E}$ ). Liquid products were analyzed by a FID GC containing a PONA colunin (HP. $50 \mathrm{~m} \times 0.20$ inm). In this study. the selectivity for dimer, truners and tetramers is described in wt $\%$. The experimental conditions were described in detail elsewhere. ${ }^{13}$

In order to recover the cataly tic activity, after deactivation which was obtained by a reaction with high WHSV. the aged catalysts were purged by flowing n-butane (flow rate: $25 \mathrm{~g} /$ h) at $70^{\circ} \mathrm{C}$ for $10 \mathrm{~h}$. The aged zeolite catalysts were also reactivated by calculion at $400^{\circ} \mathrm{C}$ for $10 \mathrm{~h}$ under the air flow $(100 \mathrm{cc} / \mathrm{nmin})$

\section{Results and Discussion}

Figure I shows the isobutene conversion and selectivities for trimers and tetramers with tme-on-stream depending on the type of catalysts. The isobutene conversions over cationexchange resin catalysts are very stable compared with those over zeolite cataly sts even though the BEA and FER zeolites show outstanding performances among various zeolites. ${ }^{16.17}$ The trimerization results over Amberlyst-35 are superior to those of Amberlyst-15 because of high acid concentration. ${ }^{20}$ The trimers selectivities over cation-exchange resin cataly sts are also superior to those over zeolites because the trimers selectivity mcreases with conversion of isobutene. ${ }^{13,17}$ Even though a detalled study is nececessary to understand the reason for the stable performance over the resin catalysts.

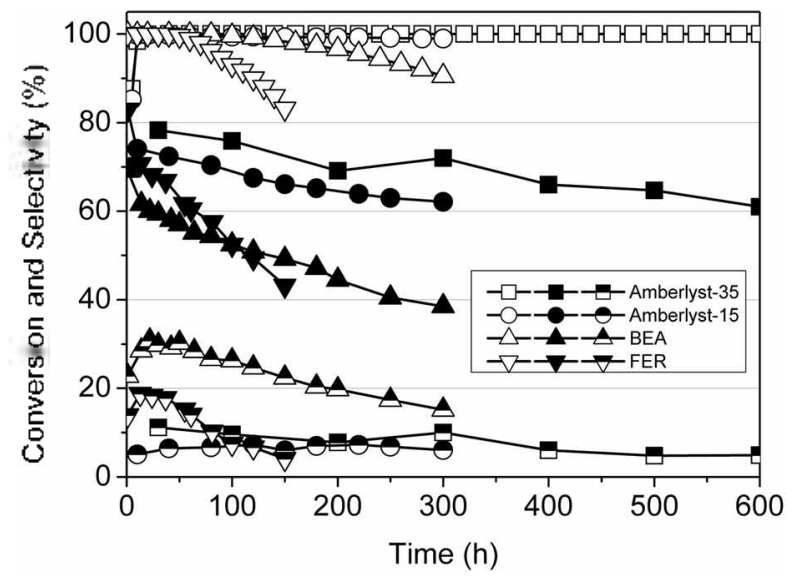

Figure 1. The isobutene conversion (empty symbols), trimers selectivity (filled symbols) and tetramers selectivity (half-filled sumbols) depending on the catalists and time-on-stream. Isobutene WHSV was $10 \mathrm{~h}^{-1}$. the macroporous structures probably have dommant effect on the stable conversion because the deactivation probably be related to the buld up of oligomeric or polymeric materials on catalysts. Moreover. the low acidity of resins. ${ }^{22}$ leading to low tetramers (or higher oligomers or polymeric materials) concentration. probably is another reason for high catalyst lifetime. The high tetramers selectivities over zeolites may also explain the rapid deactivation over zeolites due to the accumulation of oligomeric or polymeric species. The tetramers selectivity is higher for the BEA zeolite than that over FER zeolite because the pore size of BEA (12 membered nings) is larger than that of FER (I0 membered rings). Due to the large pore size, the deactivation in BEA zeolite may be slow even though the tetramers (or probably higher oligomers also) concentraion is high. Moreover, the conversion decreases rapidly in the case of zeolites having uni-dimensional channels (such as mordenite ${ }^{17}$ and SAPO-

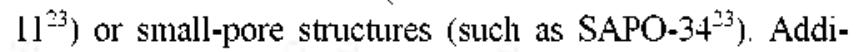
tionally. the conversion is very low in the case of non-porous gel-type cation-exchange resins such as Amberlyst-31. ${ }^{13}$ Therefore. it may be summarized that macro- or large-pores are beneficial. especially when the acid strength is not too high, for the stable isobutene conversion even though other factor such as Lewis acid-to-Bronsted acid ratio ${ }^{16-19}$ and the strength or concentration of acid sites ${ }^{\text {ij }}$ is very important for the isobutene trmerization.

Facile regeneration of an aged catalyst is very important for commercial applications especially for long-term operation. In this study, two regeneration methods (calcination at high temperature and purging with paraffin) have been tried to recover aged catalysts. The rapid catalyst aging was accomplished by the isobutene conversion with high isobutene WHSV because the deactivation of a cataly st occurrs rapidly when the space velocity is high. ${ }^{17,20}$ As shown in Figure 2. the aged BEA zeolite can recover partly its activity and selectivity by the purging with $n$-butane. However. the regenerated catalyst (by purgung) degrades the catalytic activity very rapidly. suggesting the re-activation is insuffi-

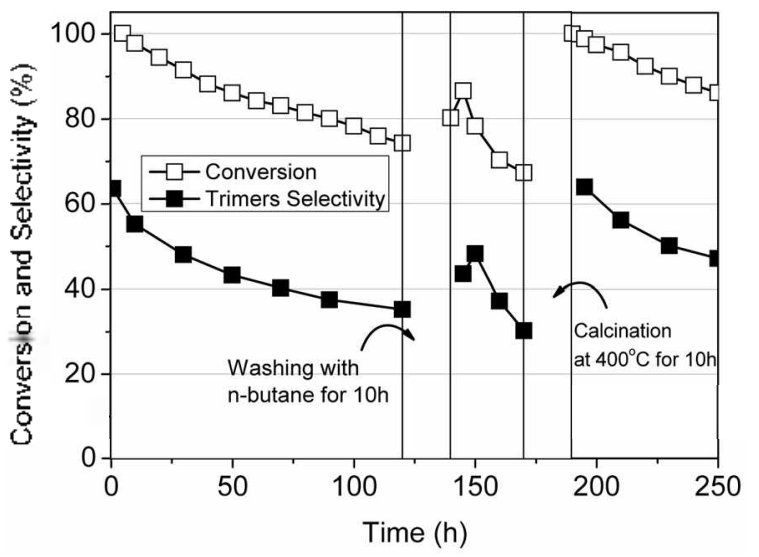

Figure 2. Conversion of isobutene and trimers selectivity over BEA zeolite with time-on-stream. The aged catalyst was regenerated by purging with $n$-butane or calcination in air at 400 ${ }^{\circ} \mathrm{C}$. Isobutene WHSV was $20 \mathrm{~h}^{-1}$. 


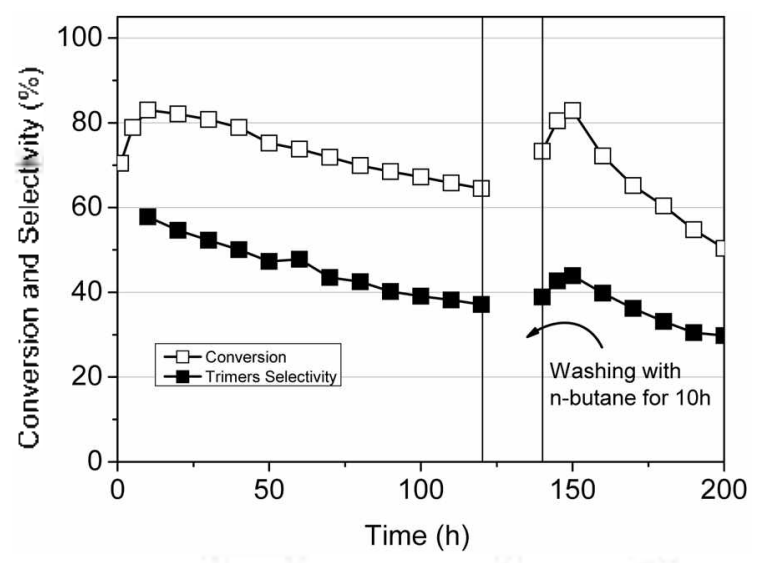

Figure 3. Conversion of lsobutene and troners selectivity over a cation-exchange resin (Amberlyst-35) with time-on-stream. The aged catalyst was regenerated by purging with $n$-butane. Isobutene WHSV was $50 \mathrm{~h}^{-1}$.

cient probably because some of oligomeric or polymeric materials adsorb strongly on active acid sites. On the contrary. the calcined BEA zeolite fully recovers the catalytic performances and the effects of time-on-stream on the conversion and trimers selectivity are very similar to those of the fresh catalyst without any contact with feeds.

As illustrated in Figure 3, the regeneration, by purging with $n$-butane. of an aged resin catalyst (Amberlyst-35) is very similar to that of an aged zeolite. The aged resin catalyst can be regenerated by paraffun purging: however. the performance degrades quite rapidly very similar to the regenerated zeolite (by purging). The recovery is complete just after purging because the pore size of the resin is very large. leading to an efficient regeneration. However. the recovery is not satisfactory for long-term operation because of rapid deactivation. Moreover. the aged resin catalyst cannot be calcined at high temperature for regeneration because the stable operation temperature of resins is limited to $150^{\circ} \mathrm{C} .2$ The marginal increase of conversion and trimers selectivity after purging with n-butane (Figures 2 and 3 ) is due to the necessary time required for the repalcement of $n$ butane by reactants. ${ }^{13}$

The two cataly'sts have pros and cons for commercial application to produce isobutene trimers. Resin catalysts have long lifetime and high trimers selectivity: however. they cannot be regenerated efficiently after deactivation due to low thermal stability. On the contrary. zeolite catalysts can be regenerated easily by simple calcination after deactivation: however. the lifetime is short and the trimers selectivity' is also relatively low. It is necessary to develop inorganic acidic catalysts to have macro- or meso-pores that show similar or superior catalytic performances to those of cationexchange resins. Alternatively, an efficient regeneration method for the aged resin catalysts is highly desirable.

\section{Conclusion}

The oligomerization of isobutene has been investigated over zeolites and cation-exchange resins to understand the pros and cons of the catalysts. Zeolite catalysts such as BEA and FER show short lifetime and low trimers selectivity probably due to relatively small pore size and strong acid sites. respectively. However. zeolites have the advantage of facile regeneration by calcination in air. Resin cataly sts have long lifetime and high trimers selectivity; however. the aged catalysts cannot be fully regenerated due to low thenmal stability. It is necessary to develop inorganic acid catalysts with macro- or meso-pores to show catalytic performances similar or superior to those of macroporous resin catalysts.

Acknowledgement. This work was supported by the Korea Ministry of Commerce, Industry and Energy (TS07503). The authors thank Dr. A. S. Mamman (NCL. India) for helpful comment including English polishing.

\section{References}

1. Mantilla. A.: Ferrat. G.: Lopez-Ontega. A.: Romero. E.: Tzompantzi. F.: Torres. M.: Ortiz-Islas. E.: Gomez. R. J. Hol. Catal A 2005. 228.333.

2. Alcantara, R.: Alcantara, E.: Canoira. L.: Franco. M. J.: Herrera. $\mathrm{M} ;$ Navarto, A. Reactive Funct. Polymer $\mathbf{2 0 0 0}, 45,19$.

3. www axens.net

4. Burnes. E.: Wichelns. D.: Hagen. J. W. Energy Pohicy 2005. 33. 1155.

5. Jeon. T.-K.: Park. S.-K.: Park. Y.-K. Catal. Today 2004. 93-95. 467.

6. Honkela, M. L.; Krause, A. O. Ind. Eng. Chem. Res. 2004. 43. 3251 .

7. Marchionna. M.: Girolamo. M. D.: Patrini. R. Catal. Todar 2001. 65.397.

8. Girolamo. M. D.: Marchionna. M. J. Mol. Catal. A 2001. 177. 33.

9. Chiche, B.: Sauvage, E.: Renzo. F. D.: Ivanova. I. I: Fajula, F. $d$. 1 fol. Catal $A 1998,13+145$.

10. Girolamo. M. D.: Lami. M.: Marchionna. M.: Percarollo. E.: Tagliabue. L.: Ancillotti. F. Ind. Eng. Chent. Res. 1997. 36. 4452 .

11. Mantilla. A.; Tzompantzi. F.: Ferrat. G.: Lopez-Ortega, A.: Romero, E.; Ortiz-Islas. E.: Gomez. R: Torres. M. Chem. Commm. 2004. 1498.

12. Mantilla. A.: Tzompantzi. F.: Ferrat. G.: Lopez-Ortega. A.: Altaro. S.: Gomez. R.: Tones. M. Catal. Today 2005. 107-108. 707.

13. Yoon1. J. W.: Chantg. T.-S.: Lee. H.-D.: Kim. T.-J.: Jhung. S. H. J. 1fol. Catal $\& 2006,260,181$

14. Japanese Patent JP 2005015383 (assigned to Idemitsu Kosan).

15. Japanese Patent JP 2005015384 (assigned to Idemitsu Kosan).

16. Yoon1. J. W.: Lee. T. H.: Chang. T.-S.: Choo. D. H.: Lee. S. T.: Jhung. S. H. J. Catal. $2007.2+5.253$.

17. Yoonl. J. W: Lee. I. H.: Chang. T.-S.: Choo. D. H.: Lee. S. I.: Jhung. S. H. Catal. Commun 2007,8,967.

18. Yoon. J. W: Jhung, S. H: Choo, D. H.: Lee. S. J.: Chang. J.S. Chem. Lett. 2007, 36. 1504.

19. Yoon. I. W.: Thung. S. H.: Choo. D. H.: Lee. S. T.: Lee. K.-Y.: Chang. T.S. Appt. Catal. A 2008. 337. 73.

20. Yoon. I. W: Jhung. S. H.: Lee. J. S.: Kimn. T.-J.: Lee. H.-D.: Chang. J.S. Bull. Kor Chem. Soc. 2007, 28. 2075.

21. Yoon. J. W.: Jhung. S. H; Lee, J. S.: Kim. T.-J.: Lee. H.-D; Chang. J.S. Bull. Kor Chem. Soc. 2008, 29.57.

22. Sharma. M. M. Reactive Funct. Polmer 1995. 26.3.

23. Yoot1. J. W. Thung. S. H.: Chang. T.S. et al Cinpublished Results. 